7 horax (1948), 3, 20.

\title{
PEPTIC ULCER OF THE OESOPHAGUS
}

BY

\author{
P. R. ALlisON \\ Leeds
}

The patient with peptic ulceration of the lower oesophagus has for a long time suffered his ulcer in a sort of "no-man's-land" to which the abdominal surgeon could not reach and to which the physician had no access. The radiologist passed it by as quickly as the force of swallowing would take him. The endoscopist saw it as through a glass darkly on the distant boundary of his territory, but was glad to withdraw to more familiar fields.

The development of a safe surgical approach to the cardia has helped to revive interest in the condition. It has been looked for with greater care. Not only has its presence been confirmed by the surgeon, but ulceration has also, all unwittingly, been produced surgically. A lack of detailed investigation in the past led to the easy assumption that the oesophagus suffered acid digestion as a result of congenital maldevelopment. Its failure to reach its full length left the fundus of the stomach in the posterior mediastinum so that the normal barriers to acid reflux were ineffective. Peptic ulcer of the oesophagus and congenitally short oesophagus became almost like the Beaver and the Butcher: "You could never meet either alone !" Although such a congenital abnormality cannot be denied, the burden of this report is that short oesophagus is usually an acquired condition due to defects in the diaphragm which allow a sliding hernia of the stomach. In the early stages the oesophagus may remain elastic so that the hernia can be reduced, but, after peptic ulceration and fibrosis have developed, permanent shortening occurs. This hernia may be present in infancy or may be acquired later in life. As will be seen, it is the predisposing cause of most peptic ulcers of the oesophagus.

In recent years the backing of clinical suspicion by accurate observation has led to more frequent diagnosis of these ulcers, and so it is that seventy- four have been studied in the thoracic surgical unit at the General Infirmary at Leeds. Four of these followed excision of the lower oesophagus and fundus of the stomach for carcinoma. Seven were found in children between the ages of six months and five years, and sixty-three were in adults. These groups will be considered separately even though the aetiological factors may be the same or similar in them all.

\section{Adult Group}

Of the sixty-three patients in this group, thirtyfour were males and twenty-nine females. The youngest was twenty-two, the oldest eighty, and the average age sixty. Fifty-six patients, or 89 per cent, were over the age of fifty. This greater tendency to ulceration in the older age groups must be remembered particularly in the differential diagnosis from carcinoma of the oesophagus. Most of the patients have been observed for some years with repeated radiological and endoscopic examination. Thirteen were diagnosed as suffering from chronic oesophagitis with recurrent acute ulceration, and fifty had chronic ulcers. It has already been pointed out (Allison, 1946) that four stages in the natural history of the disease can be observed: oesophagitis, oesophagitis with acute ulceration, oesophagitis with chronic ulcer, and healed fibrous stenosis. The last stage may never be reached or it may be replaced by perforation and death.

SyMPToMS.-Dyspepsia in one form or another was present in 74 per cent of patients. The duration varied from one to sixty years. It was variously described as heartburn, pain behind the sternum or high in the epigastrium associated with an empty stomach and relieved by alkalis, pain going through between the shoulder blades, or "wind on the stomach." Sometimes pain would 
occur in the night and patients would take alkalis or a glass of milk to the bedside with them. In some a soreness behind the sternum was felt on swallowing. Pain might be worse immediately after food, or it might be relieved by food. An attempt to analyse the types of dyspepsia was complicated by the frequent association of oesophageal ulcer with gastric, duodenal, or anastomotic ulcer or gall-bladder disease. One patient had had a duodenal ulcer and gastro-enterostomy, and had an active anastomotic ulcer at the time his oesophageal lesion was found. One patient developed dysphagia from an oesophageal ulcer of some standing only three months after partial gastrectomy for an active gastric ulcer. Many had gallstones or had had a cholecystectomy. In general, however, the types of dyspepsia from the oesophageal lesion seemed to be of three varieties : (1) high epigastric discomfort associated with high acid secretion and related to disturbances of gastric motility; (2) burning pain behind the sternum caused by acid bathing the lower end of the inflamed oesophagus; and (3) a more boring type of pain passing into the back between the shoulder blades and often made worse by flexion of the spine, possibly related to deeper penetration of the inflammation into the oesophageal wall and surrounding mediastinal tissues. It is interesting that some patients with severe dysphagia denied ever having had indigestion.

Dysphagia was the symptom that brought most of these patients to hospital. It occurred in 92 per cent. It had been present for between eight weeks and fifty years. It was usually variable, depending on the intensity of the inflammation of the oesophageal wall. There were examples of complete obstruction, perhaps lasting a few days and being relieved spontaneously; in these the lumen at the site of the ulcer was probably blocked by undigested food which later passed on. The obstruction was most often felt to be somewhere behind the lower end of the sternum, but occasionally higher up behind the manubrium. It was not uncommon for a patient to complain that the bolus of food seemed to cause an air lock and that if the wind came up the food passed on. Dysphagia was always more marked for solid food than for liquids. One important symptom of obstruction was described by the patients as "vomiting of bile." If this had been taken at its face value it would have been difficult to explain, but more detailed questioning revealed that it was in fact regurgitation of mucus. The belief that mucus is "clear bile" may be local to Yorkshire, but it is a point worthy of emphasis.
Eleven of the patients gave a history of bleeding : in one it was slight, but in the other ten it was severe enough to cause anxiety. No death from bleeding occurred in this series.

Loss of weight was in proportion to the amount of starvation. One patient complained of recurrent hiccup.

There were four whose symptoms deserve separate consideration. These people, one man and three women, all of middle age, complained that food came up as easily as it went down. They had suffered from "windy dyspepsia" and "heartburn" for many years. There was no obstruction to the swallowing of food, but some soreness behind the sternum might be felt as the bolus passed through the lower end of the oesophagus. After a meal the patient only had to lie down, or even to bend down, for the food to flow freely back into the mouth. One said that he always had to swallow his meals twice: In these patients a hernia of the stomach was associated with peptic ulceration of the lower oesophagus and an abnormally patulous cardia. No stenosis was present and the easy regurgitation could be confirmed by screening, This variety may be classed radiologically as the patulous cardia type. Clinically some distinction must be drawn between oesophageal regurgitation, vomiting, and regurgitation of food from the stomach without vomiting. There is no word to describe this last, but "ruminating" perhaps expresses it best.

Radiological APPEARANCES.-The importance of radiological technique has already been stressed by Allison, Johnstone, and Royce (1943). An accurate impression of the condition is only obtained after careful screen examination, for snap pictures may be most misleading. It is worth noting some of the more obvious pitfalls that have been encountered. When barium passes down the oesophagus into a stricture it is reduced to a thin stream which may remain thin for some distance like the water coming out of the fine nozzle of a hosepipe. A picture of this sort may suggest a stenosis 5 or 6 $\mathrm{cm}$. in length when it is in fact only as many millimetres. The real length is only found after applying abdominal pressure, with the patient lying in the Trendelenburg position, so that barium is forced back against the lower face of the stricture. Another pitfall is to confuse the shadow with the substance. The movements of barium are not necessarily the movements of viscera. What is a large and obvious hernia in the prone position may appear to be completely reduced with the patient upright ; but the movement of barium from the chest to the abdomen does not indicate that the 
stomach also has moved. Only if an opaque body is firmly attached to the viscus can its movements be so interpreted.

In all patients, except two, a "short oesophagus" has been found and a part of the stomach adjoining the cardia has been demonstrated in the mediastinum. The change from the oesophageal mucosal pattern to that of the coarse gastric folds marks the position of the cardia. If the position of the cardia remains in doubt a Cushing clip may be applied to the junction through an oesophagoscope, and the level of this clip, in relation to the mucosal pattern and the diaphragm, can be determined on the $x$-ray screen. The area of ulceration has always been found in the lower part of the oesophagus immediately above the gastric pouch. Dilatation above the stenosis has never been marked. Apart from these constant abnormalities a variety of pictures has been seen depending on the degree and stage of peptic ulceration.

A study of the appearances in this series undertaken with Dr. A. S. Johnstone shows the following main types :

1. Short oesophagus with gastric hernia, but without obvious deformity of the oesophagus (Plate XIa).-There were eight patients in this class. The radiological diagnosis was confirmed by oesophagoscopy and sometimes by the application of a Cushing clip to the cardia. In these patients the inflammatory process in the oesophagus had not penetrated deeply enough to cause stenosis, deformity, or crater. The appearances as seen through the oesophagoscope were those of leucoplakia and acute superficial erosions.

2. Stenosis of the oesophagus without short oesophagus and gastric pouch (Plate $\mathrm{XI} b$ ).-There were only two patients in whom peptic ulceration was found without hernia, and in both these the condition was confirmed by thoracotomy. The interpretation of the pictures in relation to the operative findings is difficult, but the explanation may be found in the presence of heterotopic gastric mucosa.

3. Complete oesophageal obstruction (Plate XII $a$ ).--In only two patients was this found. In them the presence of short oesophagus and gastric pouch was only determined after dilatation of the stenosis.

4. Smooth short stenosis of the oesophagus with gastric pouch (Plate XIIb).-A smooth stricture of $1.5 \mathrm{~cm}$. or less in length was put into this class, which contained seventeen examples. The smooth funnel-shaped narrowing was sometimes complicated by the presence of food residues, and where these included undigested raisins and peas, and on one occasion a plum stone, some doubt might have been felt about the diagnosis. It was usually possible to decide that the filling defect was caused by a foreign body and that the oesophageal walls were in fact smooth.

5. Smooth long stenosis (Plate XIII a).-Any stricture over $1.5 \mathrm{~cm}$. in length was considered long. There were nine patients in this class, and the lengths of the strictures were 2, 2.5, 2.5, 4, 4, 4, 6,7 , and $7.5 \mathrm{~cm}$. In addition to these nine, all of whom had a short oesophagus, a long smooth stenosis was also found in the two patients in Class 2 where no shortening of the oesophagus was present.

6. Distorted channel without stenosis but with shortening and gastric pouch (Plate XIII b).--In two patients the lower end of the oesophagus immediately above the stomach was deformed but showed a good lumen throughout. This appearance may be produced by irregular scarring or by irregular inflammatory infiltration of the oesophageal wall.

7. Irregular stenosis resembling a carcinoma (Plate XIVa).-In five patients, four men and one woman all between the ages of 58 and 70, the narrowing was so irregular as to be highly suggestive of a malignant lesion. The presence of a gastric hernia suggested that the condition might not be malignant, but oesophagoscopy and biopsy were necessary before a firm opinion could be expressed.

8. Crater (Plate XIVb). - The radiological demonstration of an ulcer crater in the oesophagus is rare as compared with the similar lesion in the stomach and duodenum. In this series it was found in five patients, and in two of them it was large enough to suggest a small diverticulum (Plate $\mathrm{XVa}$ ).

9. Patulous cardia (Plate XVb).-The four patients in this group showed a short oesophagus with gastric hernia, but the cardia itself was so wide that its exact position was difficult to determine. Barium, given when the patient was upright, passed straight through into the stomach but flowed back freely into the oesophagus in the prone position. In most patients with short oesophagus the muscular mechanism for keeping food in the stomach in the prone or Trendelenburg position fails, but when stenosis occurs this prevents much regurgitation. When no stenosis is present regurgitation is seen, but usually only in small amounts at a time and then only with gastric contractions. In the patulous cardia group, however, the barium flows back under the influence of gravity and the stomach may dispose of all its contents in this way. 

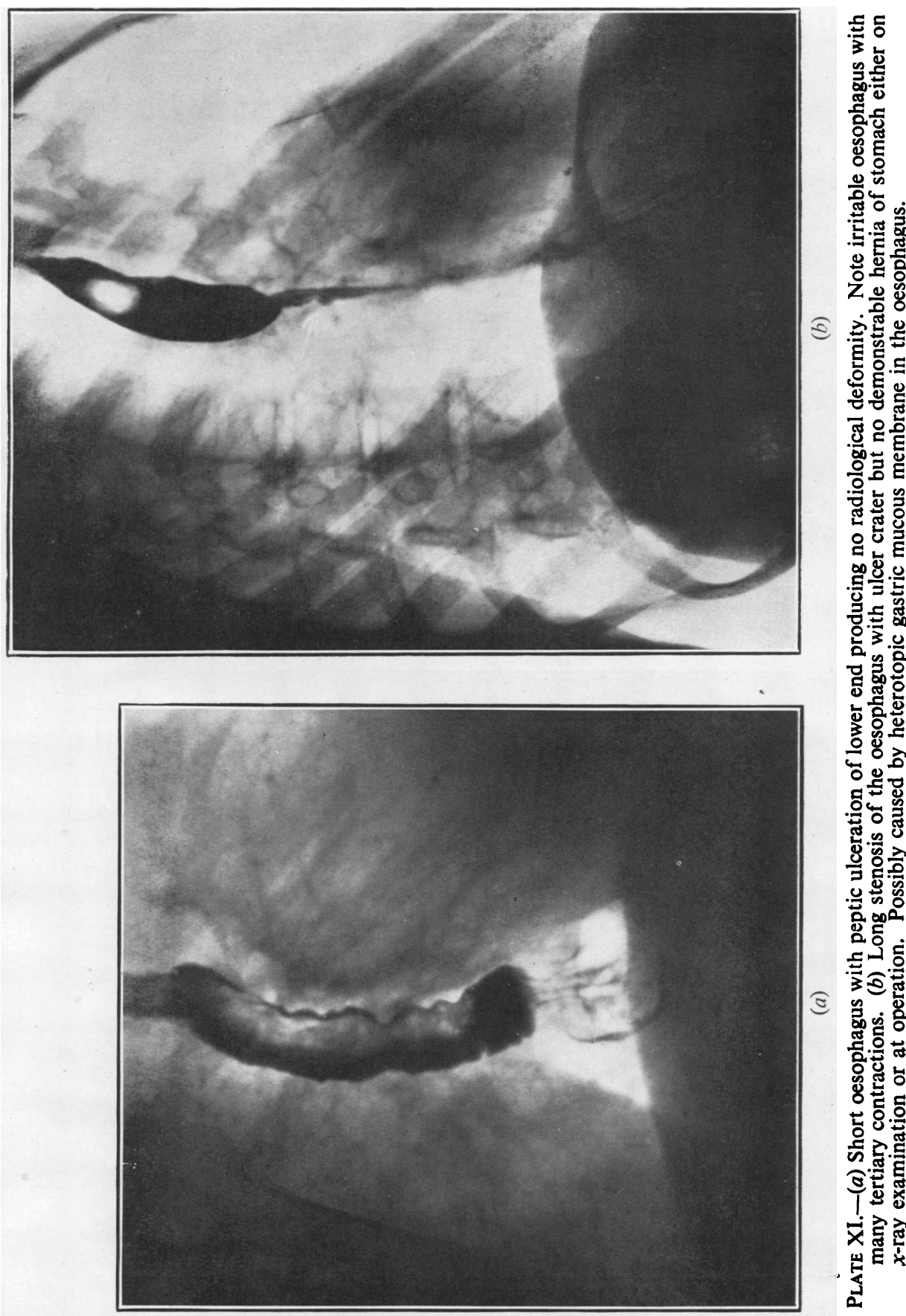


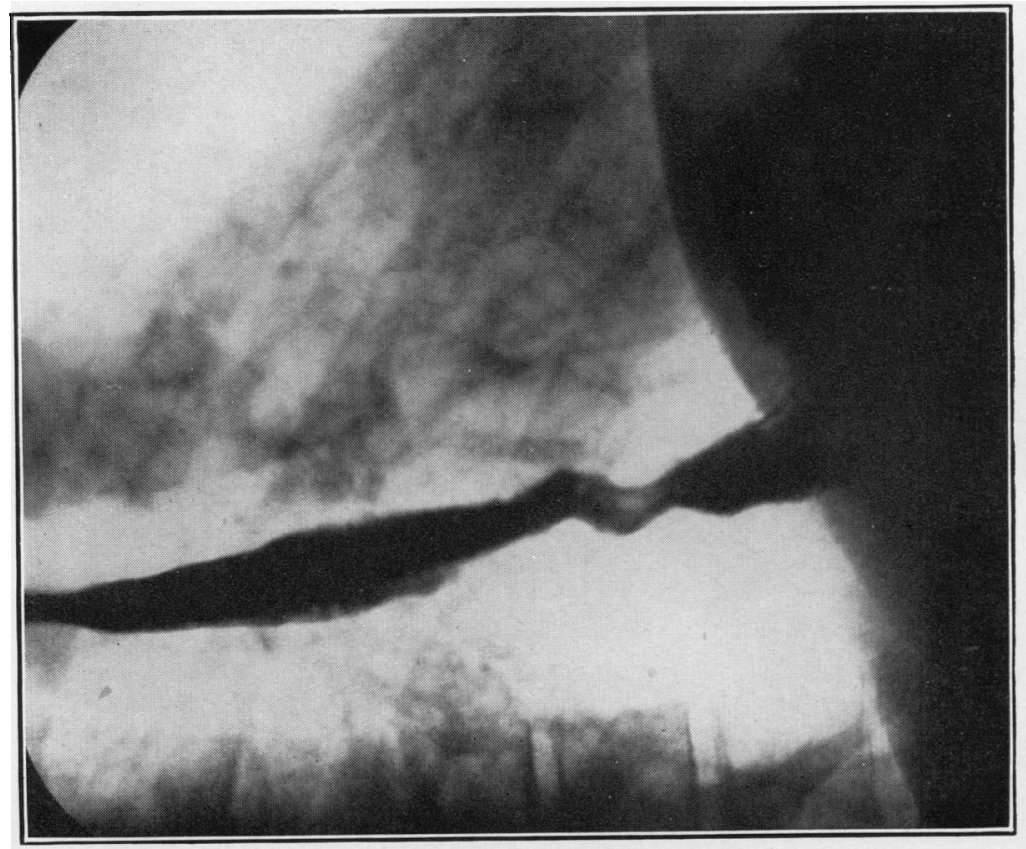

吾

(2)



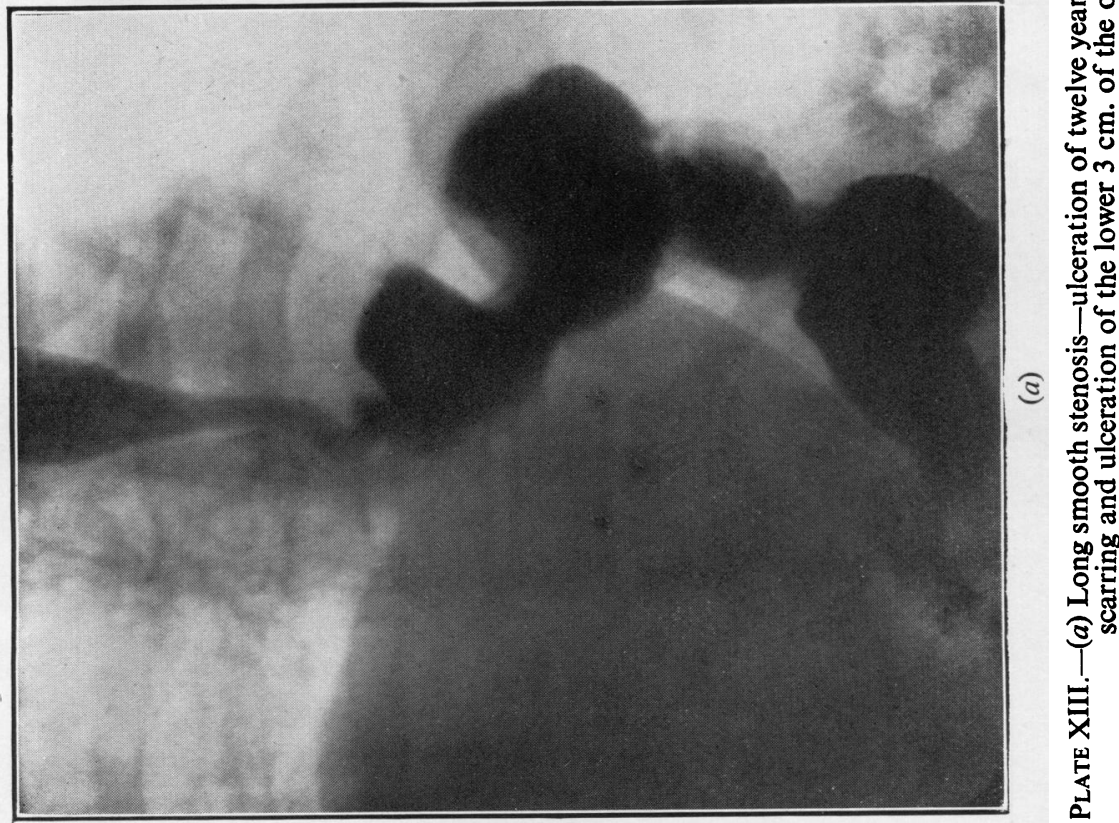



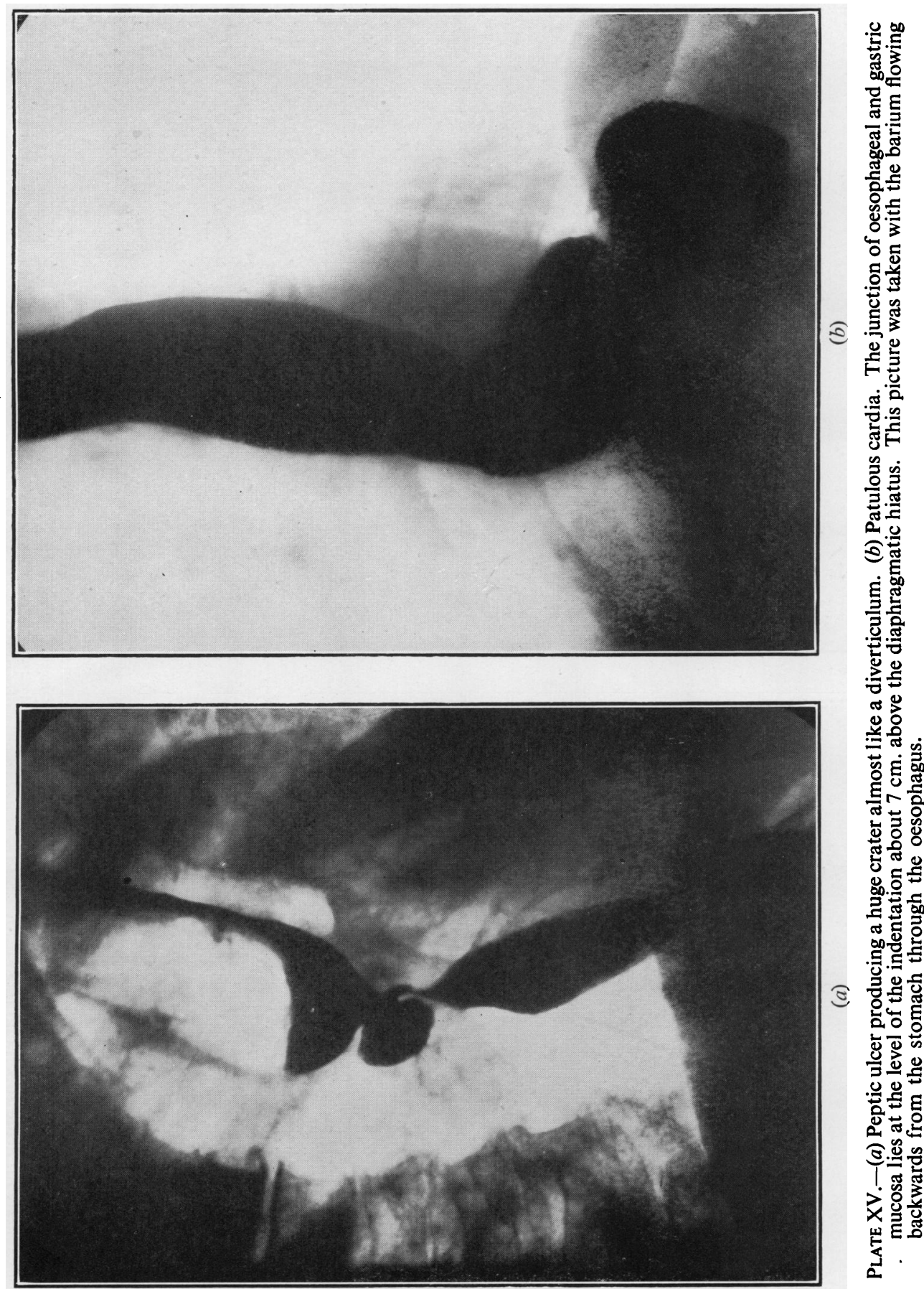


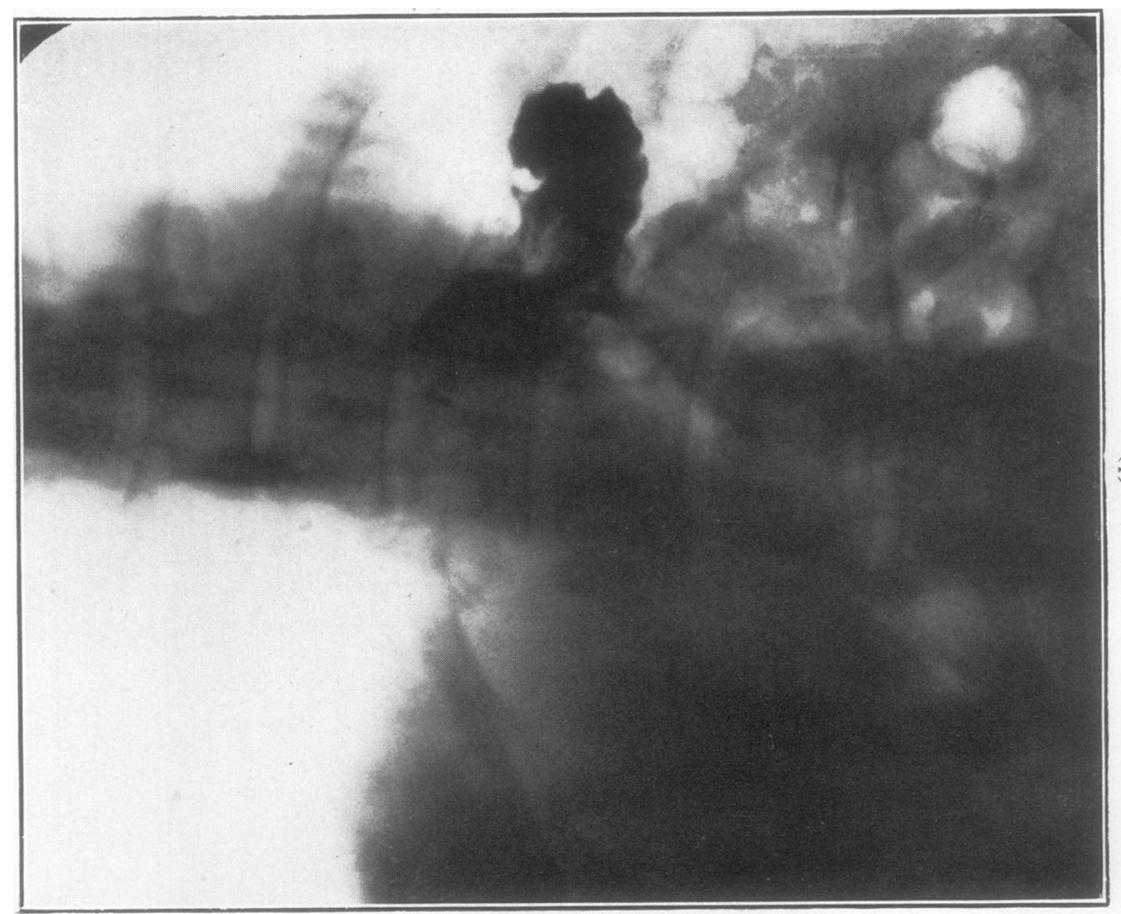

오융

종

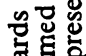

究造

응행

舟

嗮

aำ

. ․ㅡㄹ

嵒员

可

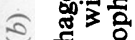

늘

O०

둥.

영도

2.

क능융

ड串

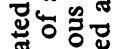

․ㅡㅇ.

ह 50

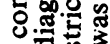

कृ

.

당흐을

政

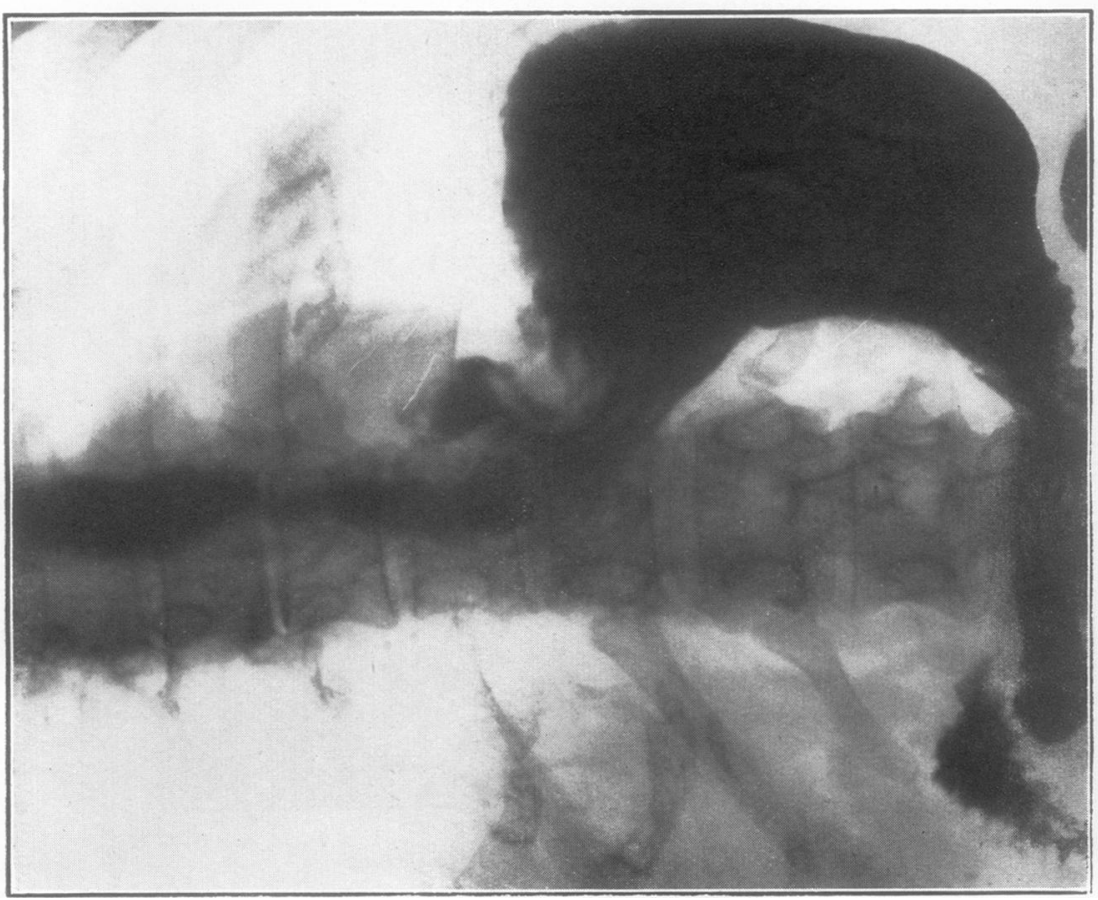

三 幽总

글

政

는을

웅등

फ

의:은

을. 동

항.를

뭉응

은원

In

6

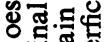

응

प्ठक के

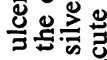

녕

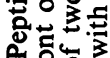

定

ใิ도웅

幽密

x。유

定 

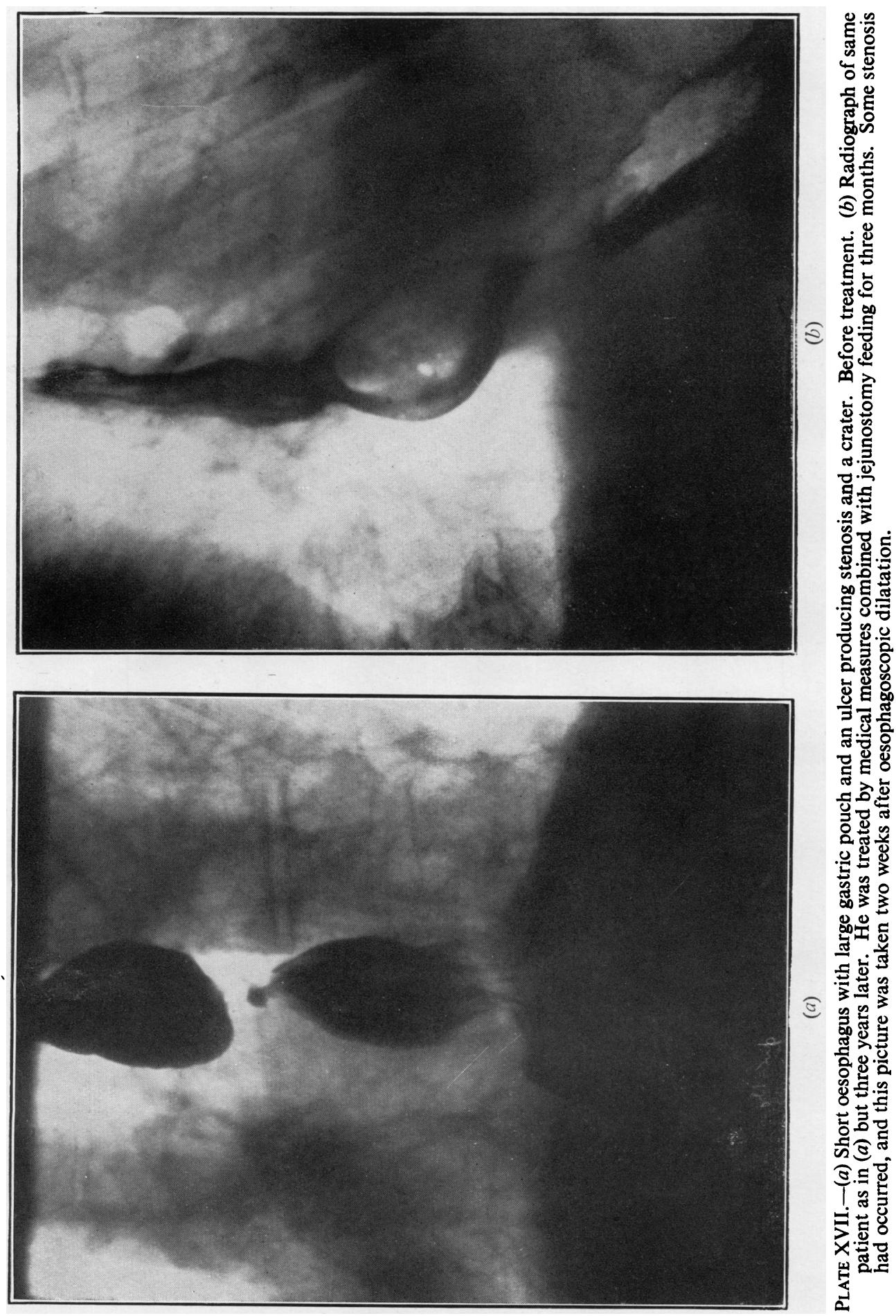


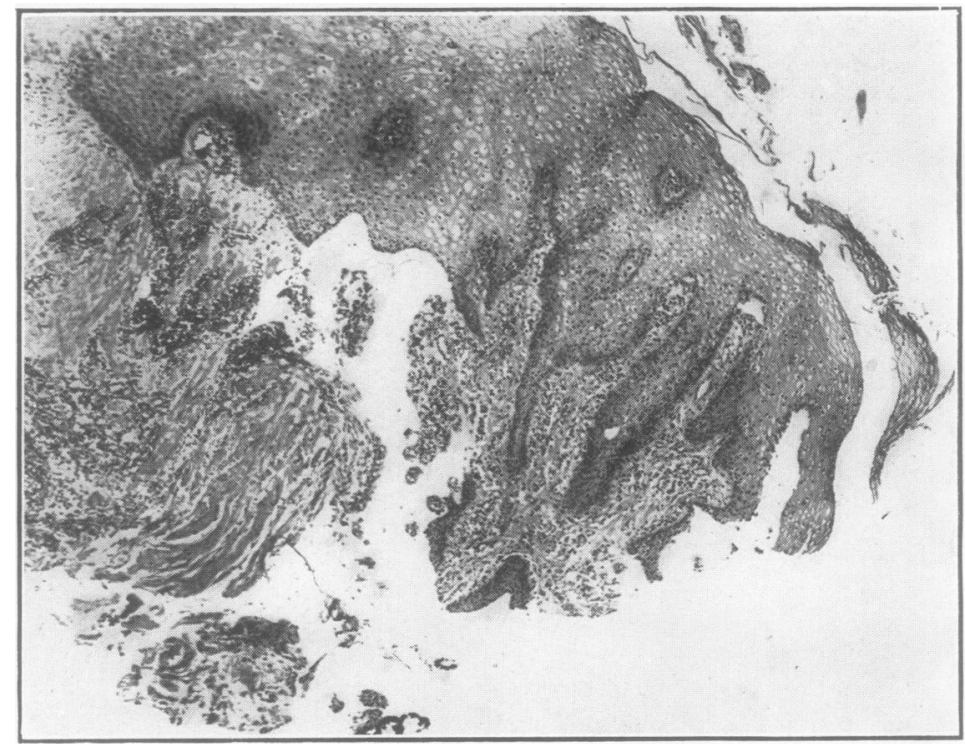

(a)

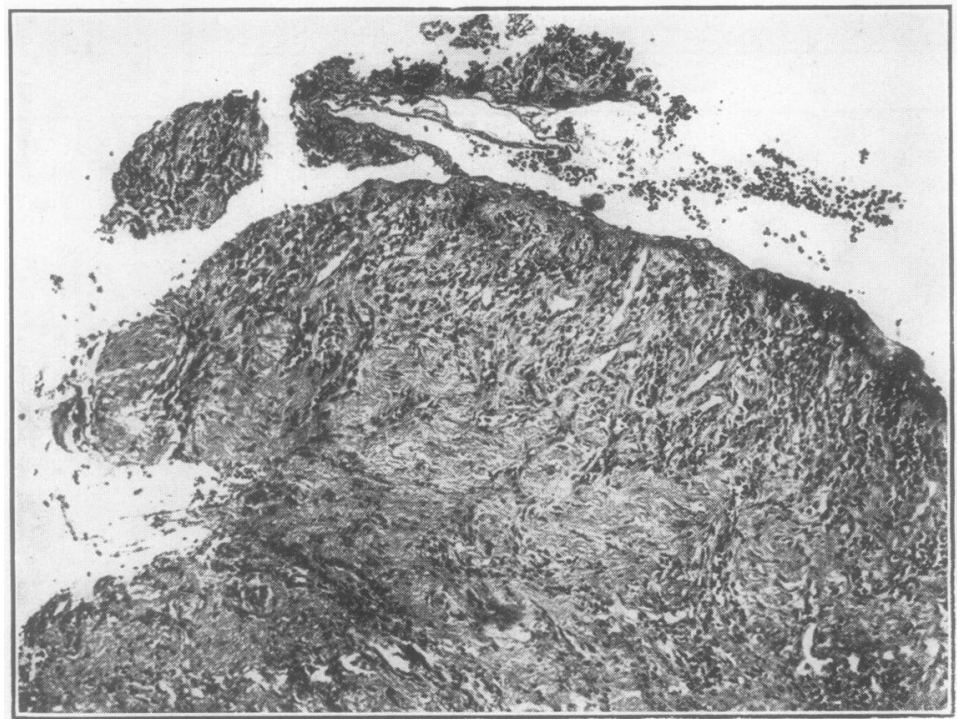

(b)

Plate XVIII.-(a) Oesophageal biopsy from the upper margin of a chronic peptic ulcer showing thickening of the squamous epithelium and prolongation of the rete pegs. Beneath this is part of the floor of the ulcer showing granulation tissue and fibrosis. (b) Oesophageal biopsy from the margin of a chronic peptic ulcer showing (right) thinning and detachment of the marginal epithelium, and (left) part of the ulcer floor, with intense inflammatory reaction. 


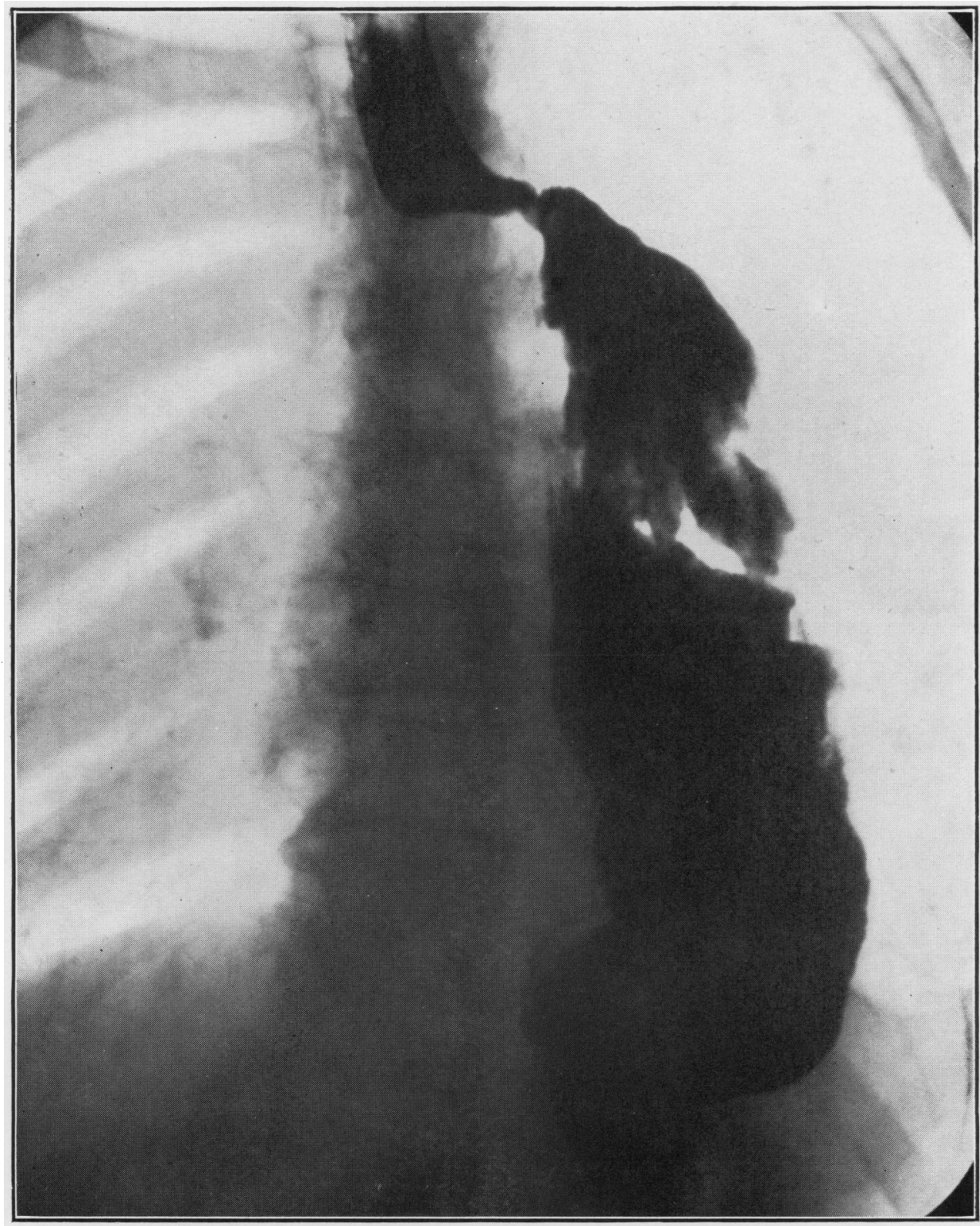

Plate XIX.-Post-operative peptic ulcer with short stenosis. This patient had had a carcinoma of the middle and lower thirds of the oesophagus removed and the stomach anastomosed to the oesophagus"outside the aortic arch. 


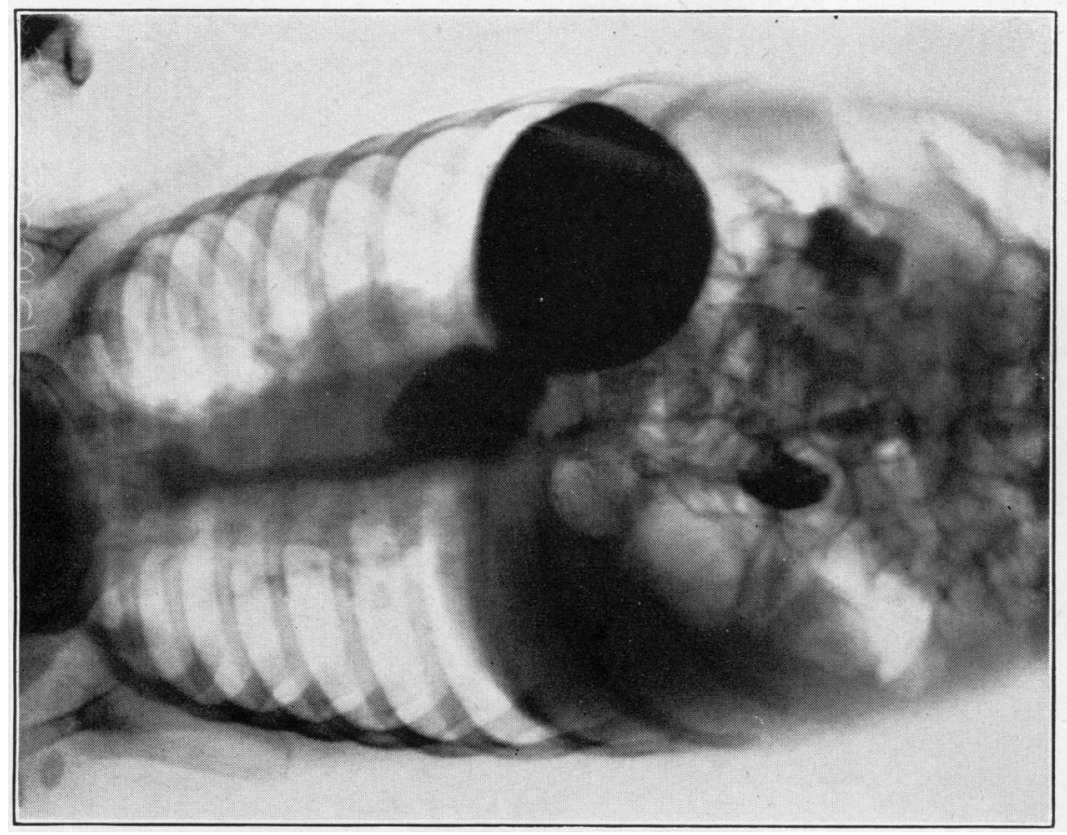

$\check{5} . \leftrightarrows \div$

穴. $\frac{n}{n:}$

言突品

든응

잉

的

는

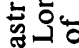

象.

它部

(2) 矛.
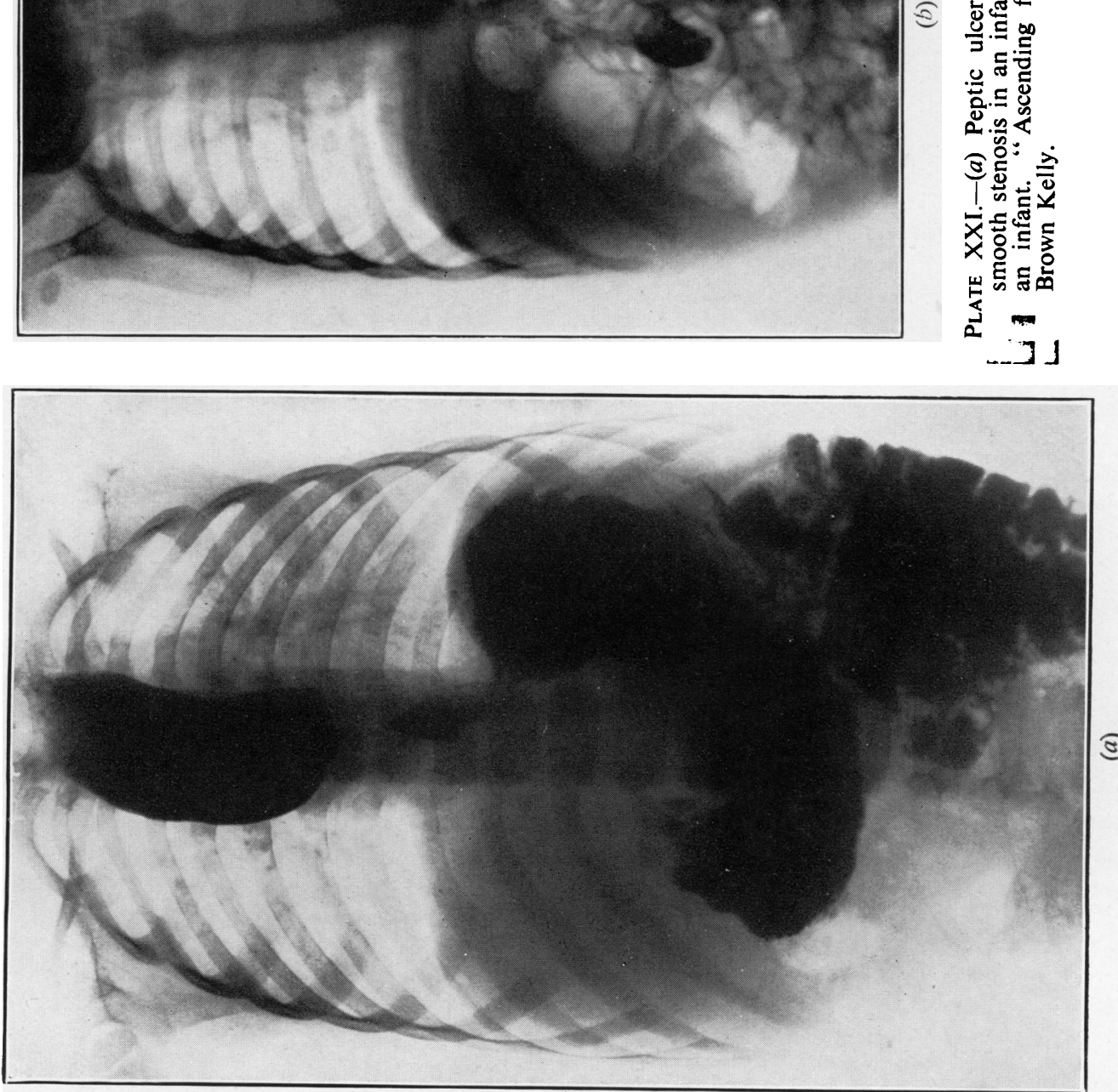

है 


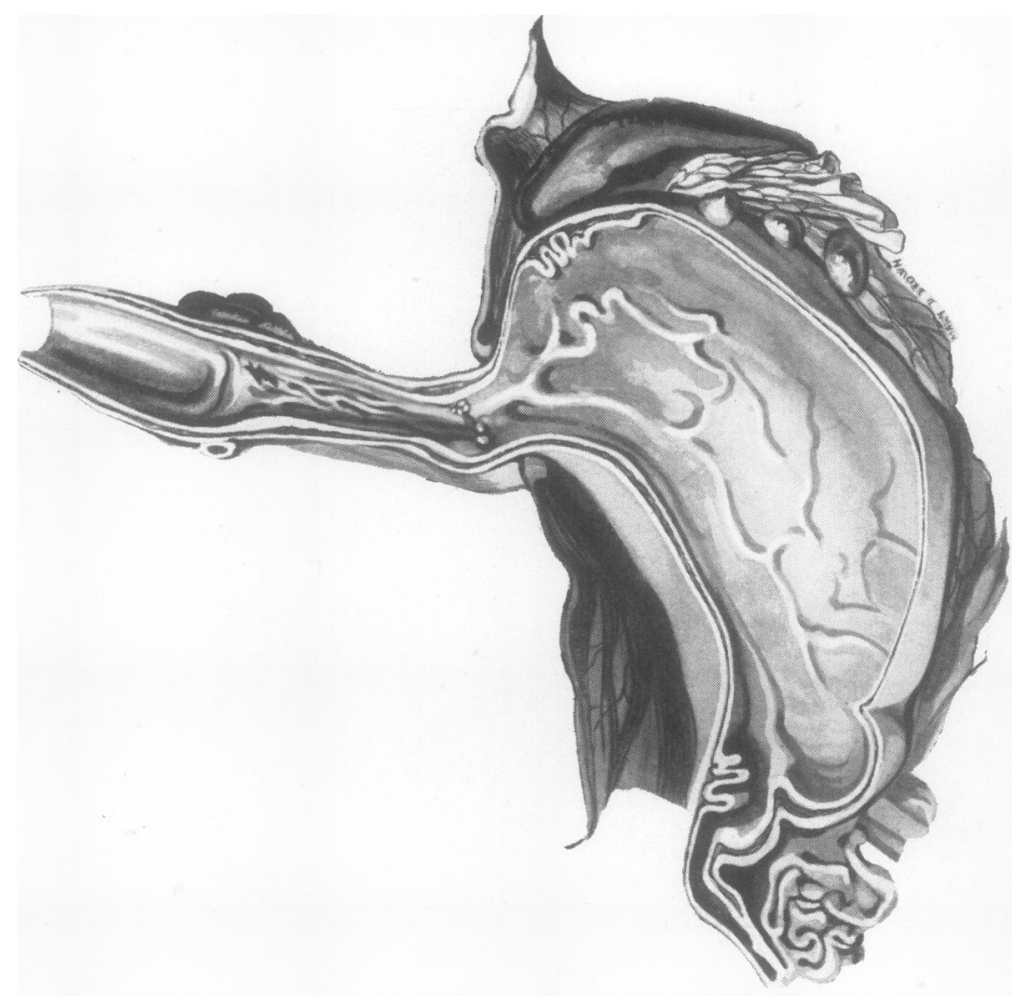

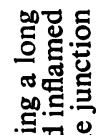

然总

옿흥

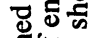

눙요

휴.응ㅎํ

E⿰讠己

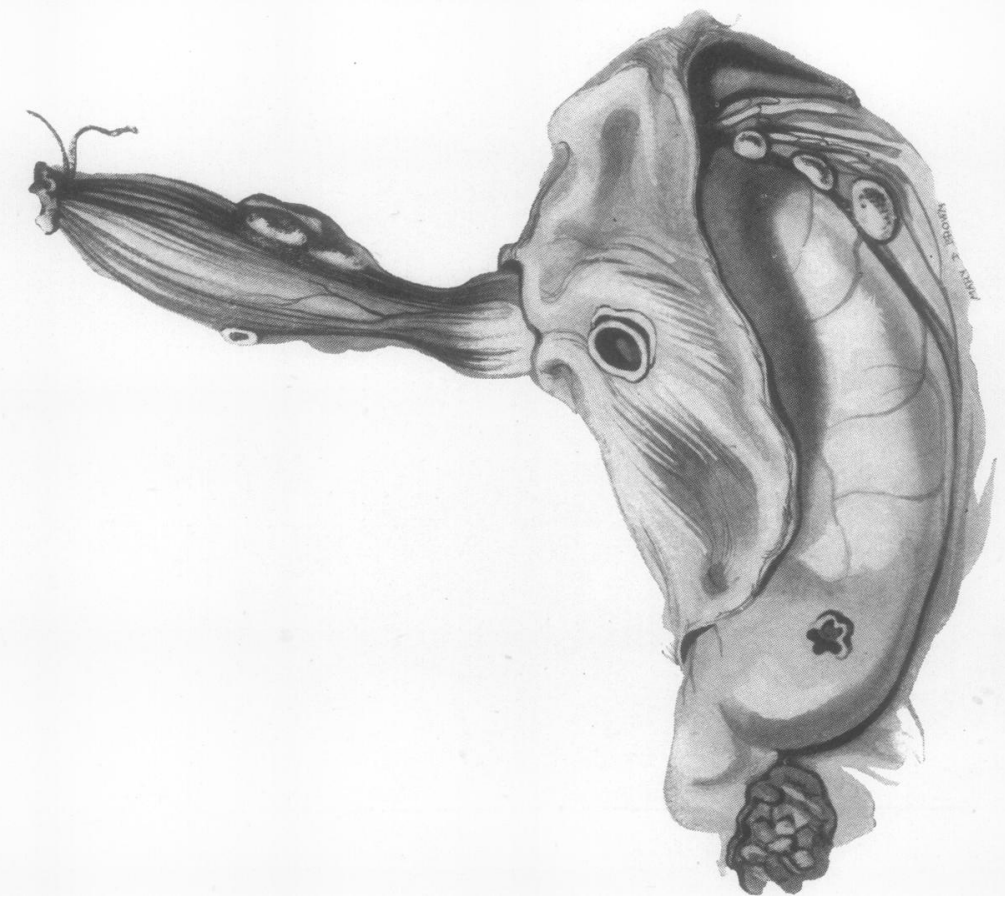

客.

올 옳

है त్

톯ำ

हैं ह

응현

氜的余

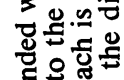

도ㅇㅝㅛ

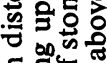

동휴

造通远

톯 氙

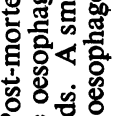

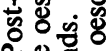

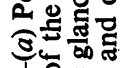

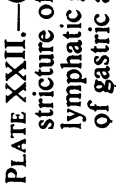



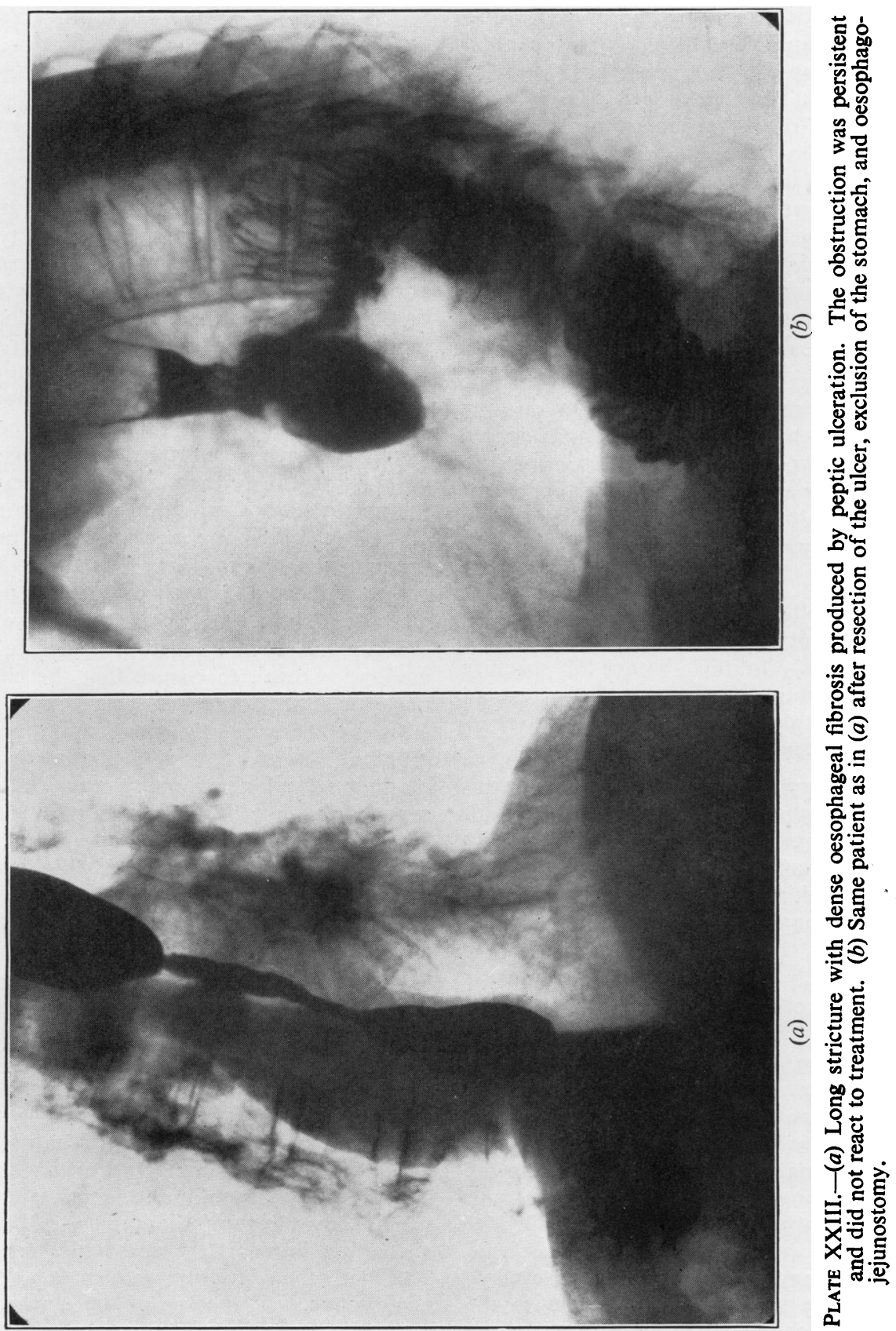
10. Associated para-oesophageal gastric hernia (Plate XVIa).--In eight patients, two of whom are represented in the other groups, the presence of a short oesophagus and gastric pouch was comp.icated by a rolling up of the anterior surface of the stomach to form a second or para-oesophageal hernia. When the para-oesophageal hernia is the more obvious lesion attention may be distracted from the position of the cardia above the diaphragm, and the presence of ulceration of the oesophagus may be overlooked. In all cases of diaphragmatic hernia the cardia should be localized exactly, and an oesophagoscopic examination performed before operation is carried out.

11. Indefinite.-This last group is filled by the radiological failures. Three patients from the present series fall into this category. In one the examination failed to show a typical appearance, and in the other two the pictures taken elsewhere had been lost and were not available for classification. It is obvious that only the most painstaking radiological technique can keep this group so small.

Oesophagoscopic ApPearances.-The appearances of the oesophagus in the presence of oesophagitis and peptic ulceration vary with the amount of stenosis. In the absence of stricture very little fluid is found in the oesophagus except in patients with patulous cardia, where free regurgitation may occur from the stomach.

In the lower oesophagus changes in the mucous membrane may be slight and only determined with certainty by histological examination. There may be thickening and congestion of the mucosa, pale patches of leucoplakia, and acute superficial ulceration. This last may be single or multiple small discrete ulcers or extensive denudation. The ulcers appear usually as pale yellowish-grey areas surrounded by a well-defined bright pink margin. When the fibrino-purulent membrane is removed by a swab the whole surface of the ulcer shows the same bright colour as the margin, and oozing of blood readily occurs. As soon as the instrument passes this area it enters the stomach without the patient's head having to be deflected. During the examination of an anatomically normal oseophagus the pinchcock constriction of the lower end by the diaphragm is noted, after which the patient's head must be depressed and moved to the right to allow the oesophagoscope to pass forwards and to the left into the stomach. At a precise moment the lumen of the viscus gapes, gastric mucosa prolapses into the field, and fluid wells up. In the patients. with short oesophagus the picture is quite different, for in the absence of stenosis the instrument is passed down from oesophagus to stomach without impediment or deflestion. The viscus is lined by oesophageal mucosa at one level and by gastric at the next; the level is higher than would be anticipated in the normal, and no pinchcock action of the diaphragm is observed. The level of the change varies with the degree of herniation, but it has been seen at $24 \mathrm{~cm}$. from the alveolar margin in a patient in whom the normal level would have been about 39 to $40 \mathrm{~cm}$. In these extreme examples there is no difficulty in making a diagnosis, but in the minimal degrees of herniation, where the change in mucosa is found at 38 or $39 \mathrm{~cm}$., the actual level of the change is less important than the way in which it occurs. If there is no deflection and the viscus appears to be a direct continuation of the oesophagus lined by gastric mucosa, and if the level of the pinchcock cannot be seen accurately, it suggests that herniation is present. In cases of doubt it may be helpful to apply a silver Cushing brain clip to the junction of gastric and oesophageal mucosa and examine the patient radiologically. These clips do no harm and soon become detached and pass on. The examination should te carried out a few hours after the clip has been applied, and before the patient has had a meal, to ensure that the clip is still in position (Plate XVIb).

In the presence of stenosis the appearances are different. There is usually a moderate collection of mucus (and occasionally food residues) in the oesophagus, but this is never gross as in cardiospasm. The mucosa of the oesophagus shows congestion all the way down, and this becomes more intense at the lower end. About 2 or $3 \mathrm{~cm}$. above the stenosis the mucous membrane shows acute congestion, often with superficial discrete ulcers or extensive denudations. These last usually have finger-like processes passing up between the pale areas of thickened, sodden oesophageal mucous membrane, and below pass into the stricture to be continuous with the chronic ulcer. The acute superficial changes immediately above the stenosis are an important diagnostic feature, for they usually indicate a simple rather than a malignant lesion. They occur in the length of oesophagus, which shows in the radiograph as a funnel-shaped narrowing immediately above the main stricture. The face of the stricture as seen through the oesophagoscope is at the top of the chronic ulcer and is usually centrally placed. The ulcer itself may not be visible. A little granulation tissue may be seen, or a superficial ulcer may pass through the stenosis. The stenosis is caused by inflammatory infiltration of the oesophageal wall around the 
ulcer. Less important factors which may play a part are polypoidal granulation tissue, muscle spasm, and enlarged lymphatic glands on the outside of the oesophagus at the site of the ulcer. These glands are always present and may form quite a large mass when the oesophagus is viewed from the outside. Whether they contribute to the stenosis is difficult to determine, but it seems likely that they may be a factor in patients where the stricture is eccentric. This has been observed particularly in young children.

When a bougie is passed into the stricture, oozing of blood occurs from the ulcer. The stenosis feels soft and uniform as distinct from the bumpy feel so often found in a malignant lesion. The length of the stricture may be gauged if the bougie is passed right through and then withdrawn until the shoulder comes up against the deep face of the lesion.

Where only a short stricture is present it may be possible to see the ulcer itself after oozing of blood has ceased, and the pouting, oedematous folds of gastric mucous membrane may show through, but in the larger strictures only a dark recess lined by bleeding granulation tissue may be visible. In patients who show a radiological picture suggestive of carcinoma, the irregularity is seen through the oesophagoscope to be produced by extensive ulceration with much granulation tissue. In no peptic ulcer has there been any difficulty in passing a bougie no matter how tortuous the channel might appear on the $x$-ray film. The oesophagoscopic appearance of a healed ulcer is that of a simple fibrous stenosis covered with pale shiny mucous membrane. It is difficult to understand how these ulcers can heal in the presence of the persistent anatomical and functional abnormality, but it seems that they sometimes do (Plate XVII $a$ and $b$ ). It may not be possible to be certain about this, because a fibrous stricture may occur at the top of the lesion and there may be persistent ulceration below. Dilatation of the stricture enough to observe this area would produce trauma which would be difficult to differentiate from peptic ulceration, but at least two patients have been observed in whom symptoms disappeared and in whom the oesophagoscopic appearances were converted into those of a simple fibrous stricture. The healing of acute superficial ulcers has been seen repeatedly.

Small punch biopsies have usually been taken and the histological appearances have varied with their exact level in relation to the ulcer (Plate XVIII $a$ and $b$ ). The difficulty of being certain about the point at which the biopsy is removed has pre- viously been mentioned (Allison and others, 1943). It has sometimes been necessary to repeat the examination to obtain histological proof that the lesion is a simple ulcer. If the biopsy is taken from the ulcer surface it may show only simple granulation tissue with or without fibrino-purulent necrotic material. Sometimes, however, the lining of the ulcer may have been wiped away by the passage of the bougies and the histological picture may be of a small fragment of dense collagenous fibrous tissue infiltrated by lymphocytes, polymorphs, and eosinophil leucocytes, or a strip of smooth muscle and chronic inflammatory tissue. A fragment from higher up will show stratified squamous epithelium with prolongation of the rete pegs and thickening of the malpighian layer; some of the superficial cells may be vacuolated and there may be hyperkeratinization; beneath and between the rete pegs there is chronic inflammatory-cell infiltration. A section from immediately below the ulcer shows intense chronic inflammation of the gastric mucosa.

\section{Post-operative Group}

The operation of partial oesophago-gastrectomy with mediastinal anastomosis for carcinoma of the cardia produces the anatomical deformity of short oesophagus and hernia of the stomach which is comparable with those already described except in certain particulars. The differences are that all the vagal fibres have been cut, a large portion of the acid-secreting part of the stomach has been removed, and a higher incidence of hypochlorhydria or even achlorhydria is probably present before operation than would be found in a series of patients without carcinoma. It is interesting to find, therefore, that some of these patients do complain of dyspepsia with heartburn after operation, many are found on subsequent examination to have oesophagitis, and some have actually developed peptic ulcer with stenosis of the lower end of the oesophagus. Of 21 patients who are alive or who survived operation long enough to succumb to secondary growths, four developed proved ulcers which caused dysphagia. A postoperative test meal with histamine showed in one of these a normal acid secretion, in one hypochlorhydria, and in the other two complete achlorhydria. These test-meal findings showed no great difference from those in patients who did not develop clinically obvious ulcers. Oesophagoscopy was not done as a routine, so there may have been ulcers present more often than is recorded. The radiological appearances were always those of a 
short stenosis (Plate XIX). The histology was identical with that already described for peptic ulcers in the adult group.

\section{INFANTILE GROUP}

Peptic ulcer with short oesophagus as a cause of dysphagia has been observed in seven children between the ages of six months and five years. Their ages were $6,10,18,18$, and 20 months, and $2 \frac{1}{2}$ and 5 years respectively. In addition to these, a child of 10 days with vomiting and haematemesis has been seen in whom a radiograph showed a typical short oesophagus. It is not included in this series because the presence of an ulcer was never confirmed by oesophagoscopy. Symptoms were first noticed at weaning. The children were reported to be sick after taking solids. They soon learnt to make themselves sick by putting their fingers down their throats, a trick which was strongly resented by the mother and which led to a diagnosis of food-forcing. They became weak, pale, and miserable. The radiological appearances were similar to those in adults. In one, complete obstruction was present (Plate $\mathrm{XX} a$ ), one had a short smooth stenosis and developed a para-oesophageal hernia while under observation (Plate $\cdot \mathbf{X X} b$ ), three had short strictures (Plate XXIa), and two long (Plate XXIb).

In five of these children the top of the stenosis was found rather high up in the mediastinum and usually about an inch below the level of the left main bronchus. It seems that the ulceration and fibrosis tend to spread up the gullet more easily in infants than in adults. This is the condition which was ably described by Brown Kelly in 1939 as "ascending fibrosis of the oesophagus in infants." It is of particular interest to paediatricians, because its early recognition may lead to surgical reduction of the hernia and, for the patient, escape from a life of dysphagia and malnutrition. It is probable in fact that these children suffer from chronic malnutrition for so long that they easily fall a prey to infections and rarely reach adult life. One of the patients in the present group developed bronchiectasis and fatal bronchopneumonia as a complication of whooping-cough. Two have been operated upon and the others are still under observation.

Although biopsies showing granulation tissue had been repeatedly obtained from these ulcers, and although the radiographs so closely resembled those seen in adults, it had not been possible to confirm the suspected pathology until one child died. The oesophagus and stomach were tied off and distended with formalin and removed from the body with the diaphragm attached. A careful dissection of the specimen (Plate XXII $a$ and $b$ ) showed it to be a true peptic ulcer from acid digestion, and Prof. M. J. Stewart's report on the histology was as follows:

"A continuous strip which included about $7.5 \mathrm{~cm}$. of the lower oesophagus and $1.5 \mathrm{~cm}$. of the cardiac end of the stomach was examined microscopically. The oesophageal lesion has the typical characters of a chronic peptic ulcer of this organ. The mucosa has been completely lost and its place taken by a narrow zone of fibrous and granulation tissue, mostly smooth on the surface and lacking the typical zone of fibrinoid necrosis of chronic peptic ulcer of the stomach and duodenum. There is, however, a very thin discontinuous necrotic layer on the surface much infiltrated by bacteria, some of which occur in large clumps. Beneath this is a cellular zone of fairly vascular granulation tissue, much infiltrated with lymphocytes, plasma cells, and polymorph leucocytes. Unstriped muscle fibres of the muscularis mucosae are present in places only. Elsewhere they have been completely destroyed. Towards the upper end of the lesion a thin layer of squamous epithelium extends for a few millimetres down over the granulation tissue layer. Beneath the granulation tissue layer there is a broad zone of very dense fibrous tissue, somewhat telangiectatic and measuring up to $2 \mathrm{~mm}$. in thickness-the much-altered submucosa : it is three to five times the thickness of the surface zone of granulation tissue.

"The muscular coat of the oesophagus still persists and in the main is well preserved. Fibrosis of the inner circular muscular layer, however, is proceeding from the broad zone of submucous fibrosis abovementioned. The outer longitudinal muscular coatmuch thinner, of course-is better preserved than the inner circular coat, from which it is separated by a narrow zone of dense fibrous tissue. In the lower part of the ulcerated lesion the necrotic surface zone becomes increasingly prominent and its content of bacterial clumps greater. The submucosa, however, is much less fibrosed and much narrower. A narrow zone of squamous epithelium is still present between the lower margin of the ulcer and the gastric mucosa, and indeed there is a detached islet of squamous epithelium lower down, with gastric mucosa on both sides of it. In this situation a portion of the diaphragm has been left attached to the gastrooesophageal wall. The change in type of the musculature of the oesophagus to that of the cardia of the stomach appears to take place exactly at the point where the mucosa changes from squamous to glandular. The portion of diaphragm itself appears to be attached to the wall a few millimetres below the gastro-oesophageal junction. A subdiaphragmatic lymph gland in this region shows an extraordinary stuffing of the peripheral lymph paths with large foamy cells. 
"In a second strip section taken from the other side of the oesophagus, a considerably larger portion of surviving oesophageal mucosa (fully $1 \mathrm{~cm}$. in width) intervenes between the lower edge of the ulcerated area of the oesophagus and the fundal mucosa. The characters of the ulcerative lesion on this side of the oesophagus are similar to those already described, except for the absence of the broad zone of fibrosis between the granulation tissue layer on the surface and the circular muscular coat. Instead, the zone of granulation tissue is much wider and the narrow zone of fibrosis is limited to the deeper part.

"The ulceration of the oesophagus, obviously chronic, differs most strikingly from the corresponding lesion in the stomach and duodenum in that the muscular coat is nowhere breached. The broad zone of dense submucous fibrosis present in the upper part of the ulcerated area of the oesophagus has sent offshoots into the circular muscular coat, most of which, however, still remains, while the outer longitudinal muscle is virtually unaffected. The ulcerative process appears to be oldest in the upper part of the lesion, where fibrosis is most advanced."

\section{Aetiology}

The only structure in the body which is known to have natural powers to resist peptic digestion is the mucous membrane of the stomach and duodenal cap. A discussion of 'peptic ulcer too often concentrates on the acid element without sufficient - reference to the factor or factors which protect the stomach. The oesophagus has no such resistance, but there is a mechanism at the cardia which normally prevents acid from reaching it. The physiology of the cardia is imperfectly understood, but observations from various sources suggest that its competence depends on more than one factor. A failure of this mechanism will allow acid to reach the oesophagus, and in time this leads inevitably to inflammation and ulceration. It is pertinent to this discussion, therefore, to inquire into the physiology of the cardia, to see how it may break down.

Mechanism of the Cardia.-If, soon after death, the stomach and oesophagus are removed, the pylorus sutured, and the organs laid on a flat bench, the stomach can be moderately distended with fluid with very little reflux into the oesophagus. As the fundus of the stomach distends, the angle between it and the oesophagus becomes more acute and a valve is produced at the cardia. The effectiveness of this valve may be increased by the elastic recoil of the oblique muscle fibres of the stomach. As these are stretched they will tend to narrow the cardia from before backwards, and the loop over the top of the cardia will accentuate the angulation between oesophagus and fundus much in the same way as the pubo-rectalis fibres of the levator ani do between the rectum and anus. During life the tonic action of these muscle fibres must be even more effective. When the organs are in the normal position in the body, the angle between the oesophagus and stomach is filled in by a thick wedge of muscle fibres of the diaphragmatic pinchcock. This also helps to maintain the angle, for the fundus of the stomach naturally passes upwards under the dome of the diaphragm while the cardia is fixed at the hiatus.

More important, however, is the way in which the lowest part of the oesophagus is enclosed in a thick-walled tunnel of the diaphragmatic crura. Herein the anatomists have been guilty of misdirection, for there is in life no such thing as the abdominal oesophagus. This part is embedded in diaphragmatic muscle except for a small triangular bare area in front, which lies beneath the peritoneum and extra-peritoneal cellular tissue. Only when the stomach is drawn forwards and downwards and the peritoneal and cellular reflections divided is an abdominal oesophagus made. This has been confirmed by dissections in the living body during the operation of partial oesophagogastrectomy, but it is also obvious during an endoscopic examination, for no sooner has the instrument passed the diaphragmatic pinchcock than the gastric mucosa is seen and acid from the stomach wells upwards.

During inspiration the negative suction force in the chest increases and the positive pressure in the abdomen increases. At this time, therefore, there is a tendency for the cardia to be drawn up into the mediastinum, or alternatively for the stomach contents to pass up into the oesophagus. But it is at this time that the crural fibres contract round the lower end of the oesophagus, closing its lumen and preventing herniation of the cardia. The muscular contraction is not equal in all directions ; it is strongest at the sides where the massive pillars of the crura lie, moderate in front, and weak behind. This can be seen through the oesophagoscope or felt with the finger in the hiatus at operation, and it is of the greatest importance in relation to operative repair in diaphragmatic hernia.

Frequent or constant presence of acid at the lower end of the oesophagus might theoretically be expected if the above factors were to fail in any of the following ways:

1. The insertion of a rigid tube through the cardia, as happens when a Souttar's tube is used for malignant obstruction. 
2. After excision of the cardia with mediastinal anastomosis of stomach and oesophagus.

3. Paralysis or lack of tone of the muscles, as happens during the slow death of the debilitated, or in some flabby, obese subjects.

4. Sliding mediastinal hernia of the cardia, where the effect of the diaphragm is lost and the angle between oesophagus and stomach is straightened out. It is notable that the para-oesophageal hiatus hernia of the stomach, where the cardia remains in its normal position, does not produce incompetence of the cardia.

5. Heterotopic gastric mucous membrane in the oesophagus, either in the form of islands or by a direct extension upwards from the stomach.

Acute or chronic peptic digestion of the oesophagus has been observed in all these conditions, and it seems that its main cause is to be found in

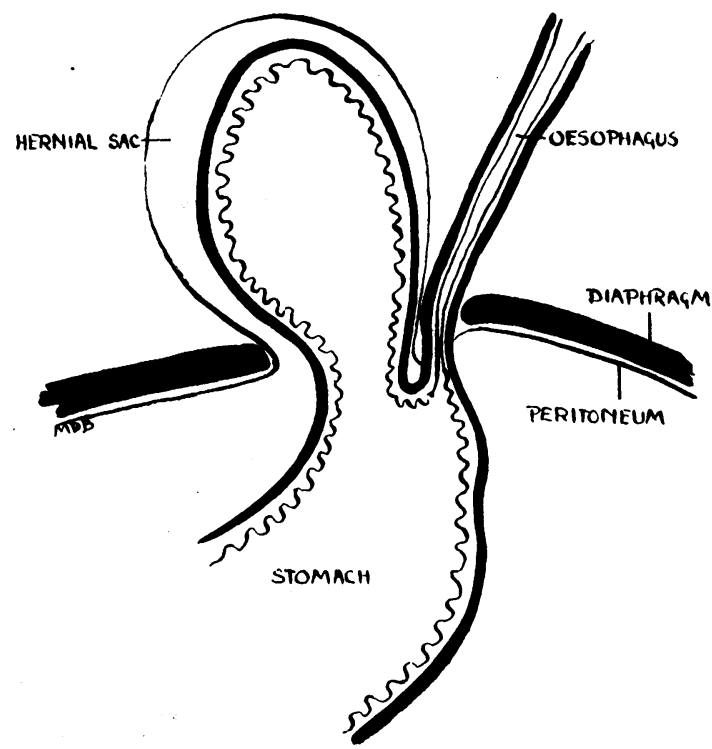

FIG. 1.-Para-oesophageal hiatal hernia.

defects of the diaphragm. The various abnormalities are illustrated in Figs. 1-5. In Fig. 1-the para-oesophageal hernia - the cardia remains below the diaphragm, the angle between oesophagus and stomach is acute, and the cardia is competent. In Fig. 2-the sliding hiatal hernia with oesophageal shortening - the whole mechanism breaks down and ulceration of the oesophagus occurs. Fig. 3 is a combination of Figs. 1 and 2 ; this abnormality is also liable to produce ulceration. Fig. 4 is comparable with a direct inguinal hernia :

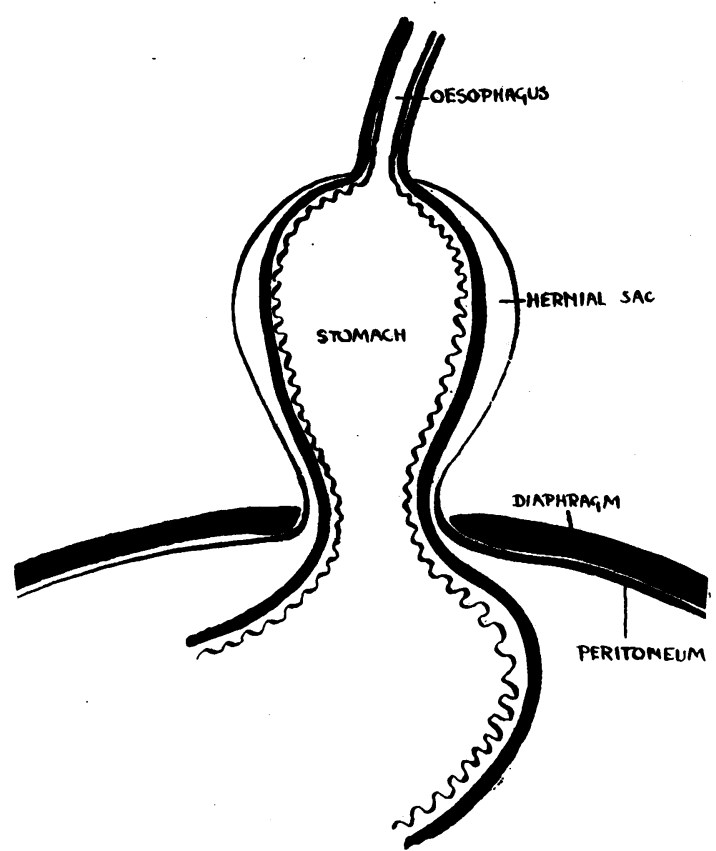

FIG. 2. --Sliding hiatal hernia with oesophageal shortening.

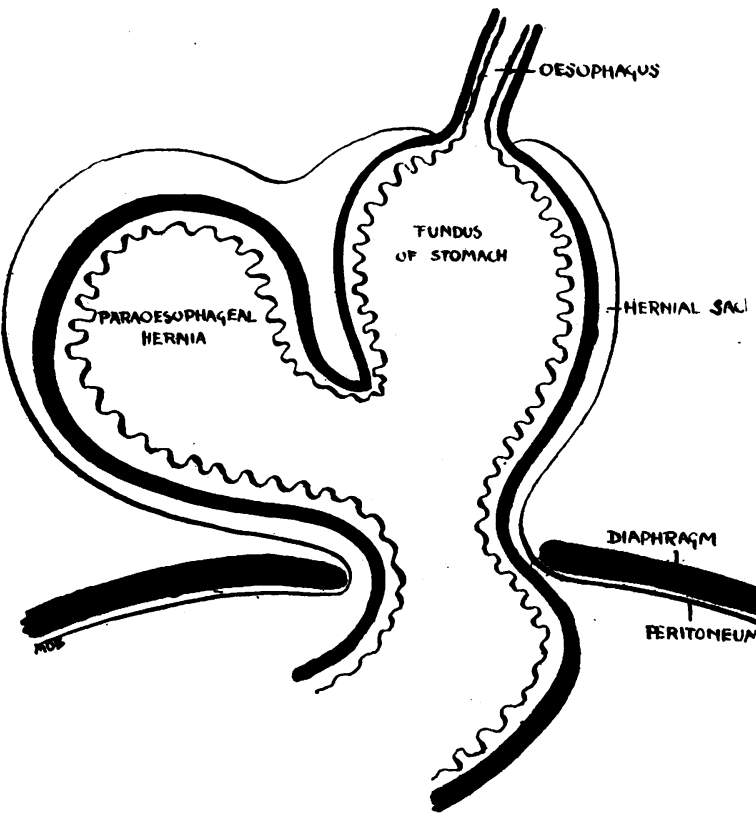

FIG. 3.-Sliding hiatal hernia complicated by para-oesophageal pouch. 
it is a conical bulging of the stomach upwards and is due to general muscle weakness; it occurs in fat and elderly people with increased abdominal pressure. Although the cardia may remain below the hiatus the pinchcock is weak, the acute angle between oesophagus and stomach is straightened out, and acid reflux occurs. Fig. 5 represents a growth or herniation of gastric mucosa above the

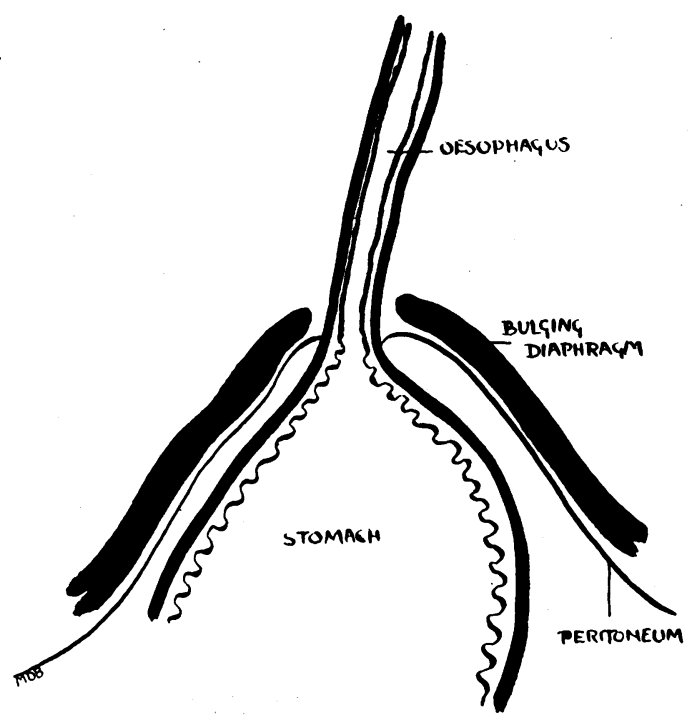

FIG. 4._" Bulging hernia."

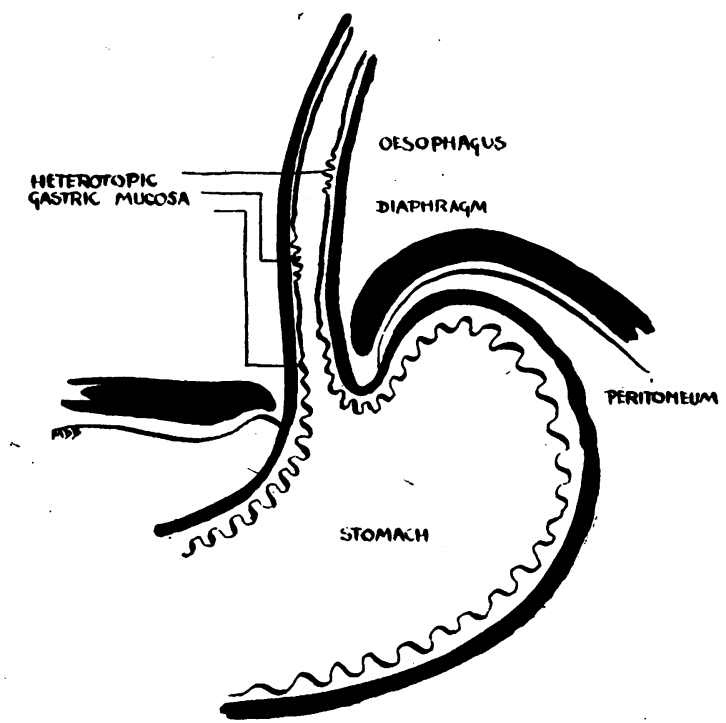

FIG, 5.-Heterotopic gastric mucous membrane without hernia. muscular mechanism. Examples of peptic u'ceration of the oesophagus are seen in the conditions represented by Figs. 2, 3, 4, and 5, but the commonest cause is the abnormality seen in Fig. 2.

If the hernia is detected while the inflammation of the oesophagus is still superficial it may be reduced below the diaphragm and the defect repaired, when healing will occur. If, however, ulceration has been either very chronic or very extensive, irreparable fibrosis of the oesophagus may occur so that it becomes permanently shortened and the hernia irreducible.

The defect in the diaphragm may be present at birth so that an infantile hernia may lead to fibrosis and fixation of the oesophagus in the first weeks or months of life. As the child grows, the herniation becomes more marked. Many of the cases described as congenitally short oesophagus come under this heading. More often, however, the hernia is acquired later in life, and most of the patients in the 50 to 70 years age group probably belong to this type. A true failure of longitudinal development of the oesophagus causing a congenital hernia may well occur, but it must be a great rarity.

\section{Treatment}

The present position of the treatment of peptic ulcer of the oesophagus has already been summarized (Allison, 1946). The rational treatment is to cure the deformity which allows acid to reach the oesophagus. The success of this depends on the oesophagus being elastic enough to reach below the diaphragm. Nine patients have been treated in this way, two children and seven adults. Of the two children, one was aged 10 months. Mobilization of the oesophagus was easy, very little fibrosis of the wall had occurred, and when oesophagoscopy was performed four weeks later the ulceration had healed. The operation was more difficult in the second child aged 4 years, for much fibrosis had led to permanent shortening of the oesophagus. The stomach remained in the abdomen, however, and the mucosal ulceration healed. It is too early yet to say if a fibrous stricture will persist. Of the seven adults operated upon in this way the stomach has remained below the diaphragm and the cardia functioned apparently normally in five. In these the ulceration healed. In one patient the hernia recurred, and in another, although the stomach remained in its normal position, such a dense fibrous stricture of the oesophagus resulted that excision was necessary.

The majority of patients have not complained of severe enough symptoms to justify operation, and 
these have been treated along medical lines already laid down, alkalis to relieve heartburn, sleeping propped up in bed to diminish acid reflux during the night, a diet chosen to avoid trauma and obstruction, and oesophagoscopic dilatation of strictures. In four patients these measures have been assisted by a period of jejunostomy feeding.

I have considered the recent use of vagotomy in the treatment of peptic ulcers of the stomach and duodenum in relation to ulcers in the oesophagus, and have rejected the procedure for the following reasons. One patient has been seen to develop peptic ulceration of the oesophagus a few months after vagotomy for a gastric ulcer ; vagotomy does nothing to alter the basic anatomical deformity which is the main cause of these lesions in the oesophagus; at least four patients have developed ulcers in the oesophagus after partial oesophagogastrectomy for carcinoma of the cardia, and these ulcers seemed to bear no relation to the acid secretion in what was left of the stomach.

The ulcerated and badly stenosed length of oesophagus has been excised in five patients (Plate XXIII $a$ and $b$ ). It does not seem reasonable to restore continuity by mediastinal gastro-oesophageal anastomosis, as this reproduces the deformity which leads to further ulceration. The oesophagus has therefore been anastomosed to a jejunal loop and the stomach excluded. Of these five patients, one died from a pulmonary embolus on the eleventh day; one recovered and put on 2 stone in weight, only to die a year later of generalized tuberculosis; and three remain well and free from symptoms.

\section{SUMMARY}

1. The symptoms, radiological and oesophagoscopic appearances, and treatment of seventy-four patients suffering from peptic ulceration of the oesophagus are described.

2. The aetiology of peptic ulcer of the oesophagus is discussed, and the suggestion made that diaphragmatic defect is the most important factor. Heterotopic gastric mucosa in the oesophagus accounts for very few. Congenitally short oesophagus occurs but rarely; it has not been seen in this series.

3. Defects in the diaphragm allow herniation of the cardia into the mediastinum and so render ineffective the mechanism for keeping acid out of the oesophagus. These herniae may be congenital (congenital short oesophagus), infantile, or acquired. There are seven examples in infants in the present series. The "acquired" group includes four patients in whom ulceration followed gastro-oesophageal anastomosis after excision of carcinoma of the cardia.

\section{REFERENCES}

Allison, P. R. (1946). J. thorac. Surg., 15, 308.

Allison, P. R., Johnstone, A. S., and Royce, G. B. (1943). J. thorac. Surg., 12, 432.

Kelly, A. Brown (1939). J. Laryng., 54, 621. 